\title{
Organophosphorous compound poisoning in cross bred cows - a case report
}

\author{
Ganga Naik*, S., Kotresh, A.M., Shambulingappa, B. E and Ananda, K.J \\ Veterinary College, \\ Karnataka Veterinary, Animal and Fisheries Sciences University, \\ Shimoga-577 204 (Karnataka) India. \\ * Corresponding author email : ganganaik2007@gmail.com
}

\section{Introduction}

Organophosphors compounds (OPCs) are used on a massive scale by farmers as ship dips, pour-ons in cattle farms, pet flea preparation and treatment of human arthropod infestation (malathion). Cattle are exposed to these insecticides either as a result of remedial measures or through accidental ingestion of contaminated feed. Death in case of organophosphorus poisoning is caused by paralysis of respiratory muscles, respiratory arrest due to failure of respiratory centre, or intense bronchoconstriction (Mosha, 1993). We encountered type of case caused by organophosphorus compounds poisoning, which proved toxic even at therapeutic doses. Here we report such a case with organophosphorus poisoning in crossbred cows in an enclosed cattle shed. Farmer used butox (Deltamethrin $1.25 \%$ ) with an intension of controlling ticks by spraying all over the walls, floor and ignorantly also on animals. Butox is available as liquid in aqueous solution containing $1.25 \% \mathrm{~W} / \mathrm{V}$ of active ingredient. This is used as a spray or dip in water (2-3 $\mathrm{ml}$ per liter of water) for the effective control of ectoparasites like ticks and flea.

\section{History and observation}

Around five cross bred cows were tied in a shed and butox was sprayed without following label on the bottle as farmer was illiterate and he did not take suggestions from concerned persons. The owner was under shock for the loss of high producing cross bred cows for his lack of knowledge in applying chemicals for the control of ectoparasites. Three deaths occurred after owner had sprayed butox (Deltamethrin $1.25 \%$ ) in closed cattle shed and two cows were sick with symptoms of dullness, depression, increased salivation, and lacrimation. The owner revealed that animals were kept in a closed shed because he believed that this may be more effective for tick control. At the time of examination two crossbred cows showed tremors, shivering, muscular spasms and rigidity of limbs. The respirations were rapid and shallow. Diarrhea in varying degrees was observed. The movements were stiff, jerky and incoordinated, particularly in the hind limbs.

\section{Discussion}

The butox (Deltamethrin 1.25\%) is usually used as spray and dip to treat the ectoparasites. As a standard practice this has to be repeated at interval of 8-10 days strictly under constant observation and following procedures in open space. Here in this case, farmer boldly used butox without following precautionary measures. When we visited the place surviving cows were immediately given atropine hydrochloride $0.25 \mathrm{mg} / \mathrm{kg}$ body weight. The one third of this dose given very slowly intravenously in a dilution $(2 \%)$ and the remainder by intramuscular injection given as reported by Radostits et al.1999. However the cows did not respond to the treatment and eventually succumbed to death.

This incident might have been avoided if butox is applied after applying the mouth cap to the animals and diluting the butox solution (2-4 $\mathrm{ml}$ of butox in one liter of water) and in open place under sunlight. Animal should be made wet and then butox should be smeared all over the body except head region and wash the animal after one hour.

\section{References}

1. Mosha R D (1993). The toxicology of organophosphorus insecticides: A review. Veterinary Bulletin CAB International, Wallingford 63: 1039-1050.

2. Otto M Radostits, Clive C Gay, Kenneth W Hinchiff, Peter D Constable. (1999). Veterinary Medicine - A Text book of the disease of cattle, horses, sheep, pigs and goats. $10^{\text {th }}$ edn, pp: 1834-1837.

$* * * * * * * *$ 